\title{
A GEOGRAFIA DA SAÚDE BRASTILEIRA E PORTUGUESA: ALGUMAS CONSIDERAÇÕES CONCEPTUAIS
}

\author{
Dirley dos Santos Vaz* \\ Paula Cristina Almeida Remoaldo**
}

\section{RESUMO}

As relações entre saúde e espaço são indissociáveis, pelo que se torna importante discutir o potencial da ciência geográfica na abordagem da saúde e avaliando-a como mais uma área de estudo na qual o Geógrafo pode intervir. Por seu turno, o espaço geográfico tem-se revelado como um importante atractivo para ciências que não o consideravam antes como crucial para a sua análise.

Quando pensamos em planeamento em saúde, a escala local surge, cada vez mais, como um determinante quando se avalia uma qualquer doença e os Sistemas de Informação Geográfica (S.I.G.) permitem-nos uma avaliação mais sustentada da realidade. Neste domínio o Geógrafo encontra-se capacitado, para em equipas multidisciplinares (sobretudo com Médicos, Economistas, Sociólogos), revelar o poder que tem a sua formação, resultante da capacidade para representar espacialmente e para usar os S.I.G. e, por outro lado, devido à sua habilidade para analisar simultaneamente a dimensão dinâmica e espacial de fenómenos como as doenças.

O presente artigo pretende analisar aspectos teóricos e metodológicos deste fecundo campo de estudos e circunscreve-se à Geografia brasileira e portuguesa.

Palavras-Chaves: Espaço, Saúde, Geografia da Saúde, Aspectos Conceptuais, Brasil, Portugal.

\section{THE GEOGRAPHY OF HEALTH AND BRAZILIAN PORTUGUESE CONCEPTUAL SOME CONSIDERATIONS}

\section{ABSTRACT}

The relationship between health and space are inseparable, and it is therefore important to discuss the potential of geographical science in addressing the health and evaluates it as another area of study in which the geographer can intervene. For its part, the geographic space has been shown to be an important attraction for science that he was not thought before how crucial for their analysis.

When we think of health planning, the local scale appears increasingly as a factor when assessing any disease and Geographic Information Systems (GIS) allow us a more sustained reality. In this area the geographer is able to in multidisciplinary teams (especially with doctors, economists, sociologists), reveal the power that has its own training, resulting from the ability to represent spatially and to use the GIS and, secondly, because of its ability to simultaneously analyze the size and spatial dynamics of phenomena such as disease. This article analyzes theoretical and methodological aspects of this fruitful field of study and is limited to the Brazilian Geography and Portuguese. Key Words: Space, Health, Geography, Health, Conceptual Aspects, Brazil, Portugal.

\footnotetext{
*Mestrando em geografia área de especialização planejamento e gestão do território pela Universidade do Minho-Portugal. email: dirleygeografia@ hotmail.com

** Professora Doutora Associada e Directora do Núcleo de Investigação em Geografia e Planeamento da Universidade do Minho Portugal. email: premoaldo@geografia.uminho.pt
} 


\section{INTRODUÇÃO}

O presente artigo pretende ser uma discussão acerca da Geografia e do seu potencial em abordar a saúde como uma área de estudo. Quer no Brasil, quer noutros países europeus (e.g., Portugal e Espanha), o espaço geográfico tem sido, cada vez mais, considerado por várias ciências, como a Medicina, a Epidemiologia, a Economia, a Sociologia e a Psicologia, que antes não o colocavam no cerne das análises que realizavam sobre doença e saúde. Todas elas faziam menção ao espaço, como uma aproximação entre outras possíveis, mas não lhe concediam uma prioridade absoluta, como sempre foi apanágio da ciência geográfica.

Por seu turno a Geografia da Saúde ganhou nas últimas décadas uma importância que não detinha antes, pelo simples facto de insistir na componente territorial e passar a dar importância ao lugar (place), por começar a utilizar ferramentas que permitem "ler" de forma mais sustentada o espaço (Sistemas de Informação Geográfica) e por ter passado a considerar, cada vez mais, as questões socioculturais.

Deste modo, o cepticismo que existia antes sobre o contributo que os Geógrafos podem dar no âmbito da saúde revela-se actualmente ultrapassado. Os Geógrafos da Saúde podem desempenhar um papel específico no conjunto das várias ciências, que resulta de aspectos metodológicos inerentes à ciência geográfica. Podem sobressair, por exemplo, a abordagem da dinâmica espacial ou a sua capacidade para representar espacialmente (cartografar), além de estarem capacitados para analisar simultaneamente a dimensão dinâmica e espacial de fenómenos como as doenças (Remoaldo, 2005, 2008). E a utilização dos Sistemas de Informação Geográfica permitiu aos Geógrafos aceder a ferramentas que são de difícil utilização por parte de grande parte dos restantes cientistas sociais e dos cientistas das ciências da saúde.

Neste novo milénio podemos afirmar que estamos perante uma nova Geografia da Saúde, que constitui uma área científica interdisciplinar, articulando e integrando vários domínios científicos (Ciências Sociais, Ciências da Terra e Ciências da Saúde). Preocupado com a dimensão e difusão de várias doenças, às mais variadas escalas geográficas, o Geógrafo tem que encarar o seu futuro como colaborante com profissionais de outras ciências, para além dos Médicos, Sociólogos e Economistas. Os Antropólogos, os Psicólogos e os Biólogos devem ser alguns deles.

Como a visão do Geógrafo é mais social, cultural e comportamental do que biomédica, ele pode dar um bom contributo à análise da doença e da saúde que se quer que seja cada vez mais holística.

Com base nestes pressupostos, o enfoque adoptado no presente artigo pauta-se pela análise das relações entre espaço e saúde, que são indissociáveis, especialmente para a Geografia, e onde o "espaço é tido como reflexo e condicionante das relações sociais" (Corrêa, 2000, p.09). Esta postura revela a importância da noção de espaço nos estudos que abordam alguma especificidade da sociedade, e deriva do pressuposto de que as relações políticas, económicas, sociais, entre outras, se vão repercutir no espaço, tido como suporte indispensável a essas relações. O enfoque seleccionado também se debruça sobre a realidade brasileira, fazendo algum paralelismo com a portuguesa, que representa a situação que se vive actualmente na Península Ibérica (Portugal e Espanha) e como país ainda periférico em termos do seu desenvolvimento em Geografia da Saúde.

\section{1-ALGUMAS CONSIDERAÇÕES DE CARÁCTER CONCEPTUAL E METODOLÓGICO}

\section{1-O ESPAÇO E A SAÚDE - BREVES REFLEXÕES CONCEPTUAIS}

O espaço geográfico tem sido usado nas mais variadas ciências, tais como, a Arquitectura, a Economia e a Sociologia, afirmando a sua característica interdisciplinar. Apresenta-se como um conceito dinâmico e multidisciplinar e tem-se mostrado apelativo para outras ciências que antes não o colocavam no cerne das suas preocupações. Podemos apontar como exemplo, a Medicina, que só muito recentemente se abriu à necessidade de estudar doenças à escala mais local e descobriu que os Sistemas de Informação Geográfica 
(S.I.G.) podem ser um importante suporte para o diagnóstico e planeamento em saúde, bem como, para entender e prever a difusão de doenças.

A Geografia tem como objecto principal de estudo o espaço, sendo incorporado em estudos no meio urbano e no meio rural, em estudos ambientais e geopolíticos. No seio do manancial de possibilidades que a Geografia oferece para a elaboração de estudos, apresenta-se o campo da saúde, onde deve deixar de ser uma mera service discipline para os profissionais da Epidemiologia, da Medicina e do Planeamento em sentido lato. Neste novo milénio o Geógrafo da Saúde deve ansiar a tornar-se num coordenador na investigação interdisciplinar em saúde. A noção de saúde para os estudos em Geografia pressupõe a sua relação directa com o espaço.

Essa situação, por si só, já apresenta um amplo e vasto campo para discussões à luz desta ciência. Diante de alguns dogmatismos epistemológicos que se vivenciaram na Geografia em períodos pretéritos, em que podemos destacar o determinismo geográfico e o possibilismo, observou-se nesta ciência um atraso metodológico. A prevalência destes paradigmas fizeram com que a Geografia fosse, durante muito tempo, uma ciência dos lugares e não do homem, ou seja, da sociedade no seu sentido stricto (Santos, 1982).

No período contemporâneo, o conceito de saúde vem apresentando um grande número de estudos e em variadas ciências. São apresentadas diferentes abordagens para o conceito de saúde respeitando-se as especificidades de cada ciência ao lidar com o conceito e demonstrando, assim, a sua riqueza.

Segundo o (Dicionário de Houaiss Língua Portuguesa, 2001, p. 2526 - Houaiss e Villar) o conceito de saúde deve ser considerado como:

Estado de equilíbrio dinâmico entre o organismo e seu ambiente, o qual mantém as características estruturais e funcionais do organismo dentro dos limites normais para a forma particular de vida (raça, gênero, espécie) e para a fase particular de seu ciclo vital.

- Estado de boa disposição física e psíquica; bem-estar.

Força física; robustez, vigor, energia.
O conceito de saúde em função do crescente número de estudos originários das mais variadas áreas, vem recebendo diferentes abordagens conceptuais e tem evoluído desde a definição mais universal elaborada em 1946 pela então criada Organização Mundial de Saúde (O.M.S.) no seio da O.N.U..

De carácter marcadamente utópico, a definição da O.M.S. avalia a saúde como um estado completo de bem-estar físico, mental e social que não pressupõe somente a ausência de doença e de incapacidade, encarando a saúde como um estado positivo que diz respeito ao indivíduo no seu todo, no contexto do seu estilo de vida. Esta definição permanece, ainda hoje em dia, um ideal, que dificilmente se atinge, porque todos os indivíduos passam por períodos, mais ou menos longos, de ausência de saúde ao longo da sua vida (Nogueira e Remoaldo, 2010).

Pode, no entanto, ser encarada como um recurso que permite a cada um desenvolver as suas potencialidades, capacitando-o para contribuir para o bem comum da humanidade (Nogueira e Remoaldo, 2010). Revela-se, cada vez mais, como um conceito dinâmico e multidimensional, sendo considerado como o equilíbrio e a harmonia de todas as possibilidades do ser humano (biológicas, psicológicas e sociais) e está-Ihe subjacente uma dimensão de potencial de vida (Martins, 2003 in Nogueira e Remoaldo, 2010).

Por último, podemos encarar o conceito de saúde como funcional e adaptativo, assumindo-se como uma construção sociocultural, que se conquista e promove e onde o espaço (físico e imaterial) desempenha um papel crucial (Nogueira, 2006).

$\mathrm{Na}$ sociedade contemporânea, onde a globalização intensifica a rapidez dos fluxos, ocasionando alteração no modos vivendi, o homem deve levar em consideração, além da ausência de enfermidade, a boa saúde física, psicológica e social, ou seja, deve eliminar factores prejudiciais à sua saúde, tais como, o stress e os hábitos sedentários.

Na Figura 1, elaborada com base no modelo construído em 1974 pelo ex-Ministro da Saúde canadiano, Lalonde, são ressaltadas 
quatro componentes que interagem e determinam o nível de saúde: biologia humana, ambiente, sistema de saúde e estilo de vida. Podemos diferenciar e ponderar as quatro componentes, se considerarmos o grau de desenvolvimento de um país ou de uma região, mas o grupo das determinantes biológicas é de difícil alteração. Podemos considerar que a Figura 1 sobressai a situação que se vive actualmente nos países mais desenvolvidos, onde o ambiente e o estilo de vida contribuem, cada vez mais, para a saúde de cada indivíduo (Nogueira e Remoaldo, 2010).

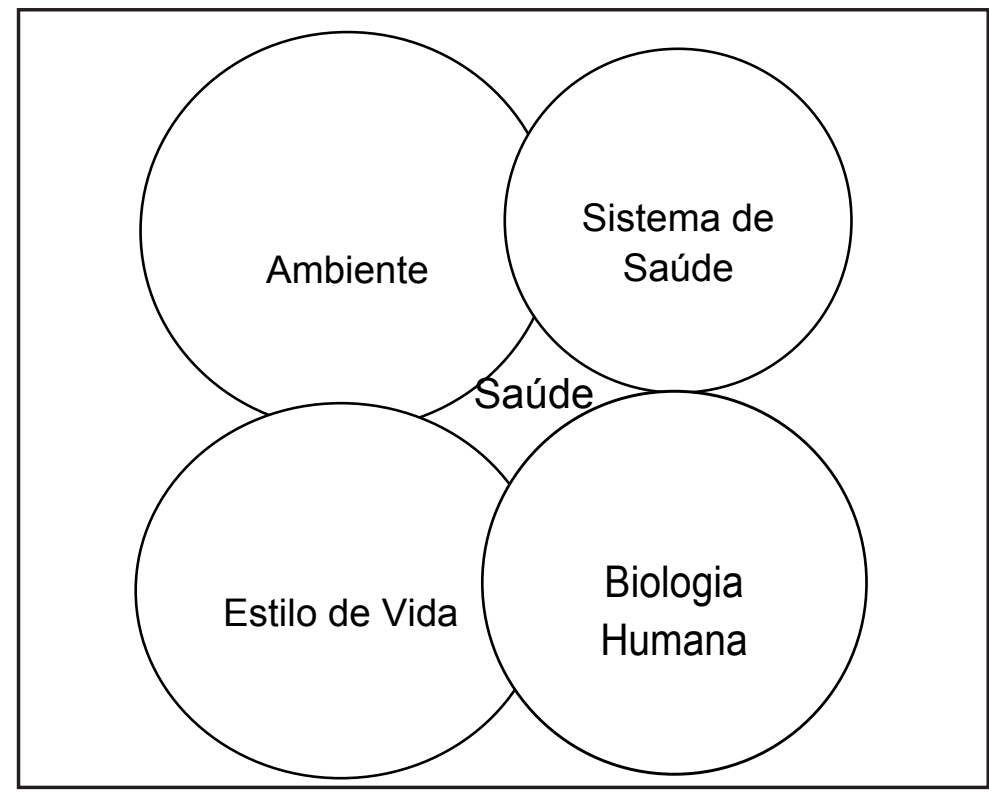

Figura 1-Determinantes de saúde - Fonte: Remoaldo

No entanto, a condição biológica continua a desempenhar um papel importante nos países menos desenvolvidos, incluindo o Brasil, e isto acontecerá enquanto o sistema de saúde não estiver desenvolvido o suficiente em termos tecnológicos e não for universal. As tecnologias inerentes, por exemplo, às Técnicas de Procriação Assistida, à Genética, à Neonatologia podem fazer uma grande diferença quando se encontram bem desenvolvidas num qualquer país, pois podem prever determinadas doenças e contribuem para o controlo de várias determinantes biológicas.

O espaço, como conceito interdisciplinar e multidisciplinar, ganha destaque, pois nele vamos observar uma série de factores positivos e negativos que influenciam a vida do indivíduo. $\mathrm{Na}$ medida em que o ambiente do homem sofre perturbações, sejam elas físicas, económicas ou sociais, pode ocorrer uma sensível alteração na saúde do indivíduo.

\section{2-A EVOLUÇÃO DAS ENFERMIDADES AO LONGO DA HISTÓRIA DA HUMANIDADE}

Ao longo da história da humanidade, várias foram as doenças que assolaram a sociedade em diferentes épocas e em diferentes proporções. Na Bíblia, por exemplo, são observadas algumas passagens que demonstram a proliferação de epidemias que atacaram povos de forma brutal.

Em alguns textos da Bíblia é possível identificar a manifestação de algumas doenças com as suas respectivas características, além do facto de que, sintomas descritos são similares a doenças 
que ocorrem ainda hoje em dia em algumas partes do mundo.

As doenças eram tidas como castigo divino cuja causa estaria em algum acto que fosse contra princípios doutrinários. Por exemplo, numa passagem do livro de Samuel menciona-se que terá Jeová, o Deus dos Hebreus, "mandado" uma doença transmitida por ratos, semelhante à peste bubônica, com o intuito de castigar os filisteus por se terem apossado da arca sagrada. Numa outra passagem da Biblía, a peste é descrita como uma praga que Deus enviou ao Egipto. A Lepra, conhecida como Hanseníase, também é muito antiga, pois é mencionada no Livro Pentateuco, do Velho Testamento.

Esse período da humanidade foi marcado pelo pouco conhecimento que se possuía em relação à transmissão de doenças, bem como, dos seus vectores de transmissão. A forma de armazenagem e estocagem de alimentos não era feita de maneira correcta. Esta situação pode ser tida em alguns casos como condição necessária para o surgimento de epidemias de proporções significativas, associadas ao surgimento de fungos e bactérias que durante muito tempo passaram despercebidos pelo homem, devido ao pouco desenvolvimento das ciências, em especial das ciências biológicas.

Na Idade Média, a história da humanidade demonstra que junto com a emergência do período conhecido como Iluminismo, a ciência ganhou importância na sistematização de informações destinadas à melhoria da qualidade de vida humana. A busca pela racionalidade conduziu ao colocar de lado alguns paradigmas em relação às doenças. Existia a crença de que as doenças, a fome, a precariedade na forma de vida da população, em especial na sociedade europeia, tinham explicação divina. Isso reflectia-se na explicação religiosa de tudo - o teocentrismo.

Outro facto interessante, sobre a disseminação de algumas doenças que assolaram o continente Europeu entre os séculos XIV e XVII, foi a esporádica falta de alimentos, seguida de graves epidemias, tal como aponta (Braudel, 1995). Segundo este autor, sempre que ocorria um período de colheita escassa, em que era deficitária a oferta de alimentos, operava-se uma redução na quantidade de calorias consumidas e uma consequência directa deste facto seria uma baixa resistência imunológica, que deixava especialmente a população pobre, sujeita a uma maior pré-disposição à incidência de doenças.

(Braudel, 1995, p. 67) alega nas suas citações que a baixa resistência imunológica estabelecida pela escassez alimentar, influenciava na multiplicação de doenças em várias regiões.

Diante desses ataques em massa, pensemos na falta de resistência de populações mal nutrida, mal protegidas. Confesso que o provérbio toscano: "O melhor remédio contra a malária é uma panela bem cheia" -que muitas vezes citei, me deixa muito convencido.

Desde o tempo de Hipócrates (480 a.C.), que os factores ambientais passaram a ter importância nas observações referentes à saúde e ao ambiente. Nesta perspectiva há estudos que enfatizaram a relação entre o clima e a influência no surgimento de algumas doenças. Os escritos de Hipócrates foram tão relevantes que propiciaram a sistematização de uma área de estudo da Medicina conhecida como Saúde Ambiental (Peiter, 2005; Ribeiro, 2004).

Nos séculos XVIII e XIX, emergem os estudos que mantiveram a forte influência dos escritos de Hipócrates, marcados pelo ambientalismo. Estes trabalhos apontam para uma maior presença da perspectiva da Geografia, onde a noção espacial começa a destacar-se, aparecendo neste período o aflorar de estudos que acabariam por ser apelidados de Topografias Médicas.

(Urteaga, 1980, p. 07), remete-nos para uma reflexão acerca da situação de miséria à qual algumas populações estavam submetidas e para a sua relação directa com uma maior susceptibilidade de contrair alguma enfermidade.

Por la misma época en que tienen gran consideración las doctrinas miasmáticas, se originan también aquellas interpretaciones de la enfermedad como fenómeno social, que alcanzaron una amplia difusión en el siglo pasado. A finales del XVIII algunos médicos atribuirán a la pobreza, el exceso de trabajo, la mala alimentación, el 
hacinamiento en barrios insalubres, y otros factores de tipo económico-social, una gran relevancia para explicar el impacto de determinadas enfermedades.

Com o processo de expansão marítima propiciada pelo capitalismo comercial a partir no século XIV, inicia-se a dispersão de novas moléstias entre os europeus e os demais povos que mantinham relações comerciais com os países europeus. Tal como aponta (Casas, 1998, p. 192):

Otro ejemplo de la influencia de los cambios ambientales sobre las enfermedades ocurrió durante el Renacimiento, cuando los viajes transcontinentales proporcionaron una nueva visión del espacio geográfico y el primer esbozo de economía mundial. Los primitivos sistemas coloniales acrecentaron no sólo el comercio y la difusión de ideas sino también la de ciertas enfermedades. La revolución comercial difundió las enfermedades por todo el planeta; la sífilis llegó al Viejo Mundo probablemente desde América (según autores habría sido llevada a Europa por los conquistadores) y la fiebre amarilla llegó a América probablemente junto con los esclavos africanos. $L a$ viruela y el cólera, endémicos del Extremo Oriente y Asia Sudoriental invadieron Europa llevadas por los barcos. En este período la difusión de las enfermedades transformó las antiguas epidemias en pandemias.

Com o aumento das viagens entre continentes, a Europa passa a receber doenças de outras regiões do planeta. Segundo (Braudel 1995, p. 67), por exemplo, a peste inglesa, seguiu a mobilidade das navegações mercantilistas "(...) segundo as lógica do tráfego, (...). Pequeno exemplo, a par desses poderosos movimentos que, a partir da China e da Índia, passando pelas escalas sempre ativas de Constantinopla e do Egito, trazem a peste para o Ocidente.

Outro exemplo do intercâmbio de doenças que ocorreu entre as diferentes regiões do planeta foi a tuberculose. Mais uma vez, (Braudel, 1995, p. 67) menciona que a tuberculose é também uma velha freqüentadora da Europa: Francisco II (meningite tuberculosa), Carlos IX (tuberculose pulmonar), Luís XII (tuberculose intestinal) são a prova disso $(1560,1574,1643)$. Mas, com o século XVII, provavelmente vinda da India, instala-se uma tuberculose que virá a ser a mais virulenta do que a que até então grassava.

Devido à ocorrência de doenças cada vez mais virulentas e maléficas para a sociedade europeia observou-se a necessidade de estabelecer medidas de protecção à escala nacional e internacional. Estas medidas contribuíram para a criação de fóruns e organismos de cooperação à escala mundial. Entre alguns objectivos que se tinham equacionado, um deles era criar condições para controlar fluxos populacionais e de mercadorias originários de outros países, pois, junto com os imigrantes e mercadorias, vinham também pequenos animais, em especial roedores, além de alguns protozoários, que são importantes vectores de transmissão de doenças.

A partir do século XIX, com a Revolução Industrial, novos padrões de doenças foram emergindo, bem como o agravamento de algumas epidemias já comuns na sociedade. Com a intensificação do trabalho industrial, a população urbana industrial aumentou consideravelmente. As cidades não estavam preparadas para absorverem todo o contingente populacional que emigrou do campo para a cidade. Além disso, não se pode ignorar a constituição de uma situação cada vez mais propícia à poluição ambiental que procedeu da Revolução Industrial e a sua implicação na causa de doenças junto da população.

No período da Revolução Industrial, ocorreu a proliferação de doenças infecciosas. Este facto pode ser atribuído à criação de condições ambientais favoráveis à disseminação de algumas doenças comuns ao meio urbano. As condições sanitárias das cidades no período da Revolução Industrial eram marcadas pelas péssimas condições de vida da população urbana. Ressalva-se que o aumento da população urbana nesta época foi rápido e intenso. Nas palavras de Casas (1998: 192):

Durante la Revolución Industrial se crearon las condiciones ambientales apropiadas para la proliferación de las enfermedades infectocontagiosas. El crecimiento urbano, las condiciones insalubres de las viviendas y el 
hacinamiento en los lugares de trabajo eran apropiados para que el llamado mal del siglo, la tuberculosis, hiciera estragos en la población. Sin embargo, un viejo enemigo, la peste, desapareció de Europa, probablemente debido al mismo procuro de urbanización y al cambio en la concepción de las viviendas (ahora sin granero en la parte inferior) que favoreció el reemplazo de la rata negra por la rata gris de Noruega, más adaptada a la vida urbana.

Tal como aponta (Peiter, 2005), esse período da história engendrou na sociedade pós-iluminismo novos hábitos. Paralelamente, a evolução das ciências ajudaram a amenizar algumas enfermidades comuns na sociedade. A medicina sanitária surgiu neste período, usandose a prática de formas de controlo epidemiológico simples, tais como, o isolamento de áreas de ocorrência de doenças, a quarentena e o maior controlo com viajantes vindos de outras regiões.

A evolução da ciência acabou por construir novas formas de estudar as doenças. O desenvolvimento de estudos biológicos mais profundos orientou o surgimento de estudos de vírus e bactérias que influíram na proliferação de doenças, bem como, os seus respectivos vectores de transmissão ajudaram a estabelecer condições para a prevenção de algumas doenças.

O período moderno de saúde pública teve início nas cidades europeias do século XIX sob as forças geradas pelo processo de industrialização. A Revolução Industrial trouxe consigo a pobreza crescente e o aumento desenfreado da população proporcionando uma significativa deterioração da vida nas cidades industriais. Situação emblemática foi a da Inglaterra, onde se notou uma concentração populacional nas cidades de Manchester e de Londres, a par da localização das primeiras indústrias. Na medida em que aumentava a população aumentavam os problemas relacionados com a saúde dos trabalhadores e estes procuraram abrigos nos arredores das fábricas. Naquela época, a preocupação financeira de muitos políticos, representantes dessa população, impossibilitou que se aprovassem medidas de higiene pública.

Por volta de 1866 , o poder público coordenou a construção de redes de esgoto e água, antes monopolizadas pelas empresas privadas. Fazendo uma analogia com a situação acima descrita na Inglaterra, verifica-se que ainda hoje, muitos países do terceiro mundo ficam impossibilitados de tomar medidas de saúde pública nas suas cidades mais importantes. Isso tem sido intensificado pelos interesses económicos constantes mantidos através da pressão financeira, agora implementada pela globalização. Assim, mantém-se o ciclo do caos urbano com moradias inadequadas, pobreza, má higiene e doenças. (Ribeiro, 2004) usando uma citação de Engels descreve as características ambientais das cidades industriais inglesas da seguinte forma (Engels, 1986: 38, in Ribeiro, 2004):

Todas as grandes cidades possuem um ou vários bairros de má reputação - onde se concentra a classe operária (...). Habitualmente, as próprias ruas não são planas nem pavimentadas; são sujas, cheias de detritos vegetais e animais, sem esgotos nem canais de escoamento, mas em contrapartida semeadas de charcos estagnados e fétidos. Além disso, a ventilação torna-se difícil, pela má e confusa construção de todo o bairro, e como vivem muitas pessoas num pequeno espaço, é fácil imaginar o ar que se respira nestes bairros operários.

A qualidade de vida era precária e a esperança de vida era baixa, enquanto as taxas de natalidade e de mortalidade eram elevadas. A má qualidade de vida de grande parte da população foi agravada devido às condições sanitárias e ambientais originárias das cidades que não dispunham de infra-estruturas básicas que proporcionassem cidades saudáveis.

Sendo assim, até àquele período assistimos à Primeira Era da Saúde Pública, que não é mais do que a primeira fase da Teoria da Transição Epidemiológica. Esta caracterizouse pelo predomínio das doenças infecciosas e parasitárias (as mais mortíferas eram a tuberculose, a pneumonia e o paludismo), das doenças por carência alimentar (desnutrição, deficiências calórico-proteicas, avitaminoses) e pela ausência de higienização do meio ambiente (e.g., saneamento, rede pública de abastecimento 
de água) e dos locais de trabalho. Também não podemos esquecer o problema das diarreias infantis, que estavam frequentemente ligadas a deficiências nutricionais.

De acordo com Pickenhayn (2006), com a evolução dos estudos em saúde, no século XIX, foi observada uma mudança significativa nos saberes em relação às doenças, em especial na relação meio ambiente e doença. Isto foi caracterizado por (Pickenhayn, 2006, p. 261) como:

Esta mística llegó al siglo XIX, cuando los avances tecnológicos ampliaron las fronteras de la medicina produciendo resultados importantes. Micróbios y miasmas, agentes a los que se atribuyeron las causas de lãs epidemias, difundieron, además de las pestes, una enconada controvérsia entre los médicos.

A reforma urbana originária das cidades européias do século XIX, decorreu, em especial, da cidade de Paris que serviu de base para uma melhoria nos padrões de vida das populações urbanas do final do século XIX. Entre 1853 e 1869, o Barão Haussmann, citado por Le Corbusier (2000), foi considerado um dos percussores do planeamento racional do espaço, tendo na cidade de Paris uma referência. Tal como aponta Le Corbusier (2000), devido aos grandes problemas que o ambiente urbano propiciava, foi necessária "uma verdadeira cirurgia no espaço", afim de se mitigar problemas relacionados com a ocupação irregular em diferentes áreas da cidade. O resultado dessas ocupações irregulares era observado, por exemplo, no mau funcionamento do trânsito, espaço com poucas infras-estruturas, precário saneamento, caracterizando-se por serem territórios insalubres à ocupação.

No período entre a primeira e segunda Grandes Guerras Mundiais, ocorreram milhares de mortes na Europa. Neste período assistiu-se, sobretudo, à escassez de alimentos e a um elevado número de vítimas mortais, que associados a fracas infra-esfraestruturas (e.g., saneamento, destruição das habitações) e a uma má condição ambiental (e.g., poluição, baixos níveis de assepsia) propiciaram o desencadeamento de epidemias.

Após o período de guerra a sociedade contemporânea entrou numa nova fase epidemiológica e várias doenças foram descobertas. Em paralelo com a evolução das técnicas, bem como, de medidas para se evitar a transmissão de doenças, a descoberta de vacinas auxiliou na extinção de doenças, em várias partes do mundo, tais como, a tuberculose e a febre amarela.

Sendo assim, depois de um longo período de elevada mortalidade, uma baixa esperança de vida e um predomínio das doenças infecciosas e de nutrição, onde os recém-nascidos, as crianças pequenas, as mulheres grávidas e lactentes, os adultos em profissões de risco e os idosos eram os mais atingidos passamos para uma nova fase. Nesta segunda fase observa-se o declínio daquele tipo de patologias, um aumento da esperança de vida e uma maior frequência das doenças crónicodegenerativas (e.g., os tumores, os acidentes cardio e cérebro-vasculares - Remoaldo, 2008). Esta segunda fase, equivale à transição epidemiológica propriamente dita, e foi apelidada de Segunda Era da Saúde Pública. Iniciou-se após a segunda Guerra Mundial nos países mais desenvolvidos, mas foi mais evidente a partir da década de sessenta e de setenta, em vários países europeus, tais como Portugal. Revela o desenvolvimento de novos tipos de doenças e de outras existentes, que eram antes pouco representativas (e.g., a obesidade, a diabetes, a hipertensão, as afecções cardiovasculares e cérebro-vasculares, os tumores).

O processo de urbanização que ocorreu nos países capitalistas periféricos, a partir da segunda metade do século $X X$, trouxe impactos nos perfis de morbimortalidade das populações. Esses impactos colocaram a questão urbana na agenda da saúde. A cidade tornou-se o local por excelência de desigualdade e pobreza. Como afirma (Santos, 2004, p. 10):

A cidade em si, como relação social e como materialidade, tornou-se criadora de pobreza, tanto pelo modelo socioeconômico de que é o suporte como por ter sua 
estrutura física, que faz dos habitantes das periferias (e dos cortiços) pessoas ainda mais pobres. A pobreza não é apenas o fato do modelo socioeconômico vigente, mas também, do modelo espacial.

Surgiu, entretanto, uma grave doença que ainda continua a ser uma ameaça para a humanidade que é a A.I.D.S.. A sua progressiva perpetuação na história da sociedade vem preocupando principalmente os países do continente Africano. É perceptível o surgimento de um novo padrão de doenças, pois além de factores físicos na disseminação de doenças, percebemos o aflorar de enfermidades associadas ao modo de vida, principalmente, da população urbana. Factores como o stress, os maus hábitos alimentares, o sedentarismo, ajudam na manifestação de moléstias que quase sempre não demonstram sinais tão claros de enfermidades quanto as doenças precedentes do século passado.

Tal como menciona (Almeida, 2005, p. 406):

A transição epidemiológica é um processo mundial de mudanças na qualidade da saúde das sociedades. Ela é caracterizada pela diminuição expressiva da mortalidade infantil, da morbimortalidade por doenças infecciosas e parasitárias e pelo aumento da morbimortalidade por doenças crônico-degenerativas e pelo crescimento da violência nos centros urbanos.

A mesma autora ressalva um novo factor de destaque no padrão de mortalidade proveniente de causas induzidas, ou seja, factores como os acidentes e as Doenças Sexualmente Transmissíveis, que imperam na sociedade contemporânea. Segundo (Almeida, 2005, p. 406):
Nos países desenvolvidos que passaram pela transição epidemiológica os grandes problemas de saúde enfrentados pela população são principalmente: o câncer, os problemas do sistema neurológicos e dos aparelhos circulatório, digestivo e geniturinário. Além dessas doenças não-transmissíveis, há ainda os problemas de saúde por causas externas, como por exemplo, os homicídios e os acidentes de trânsito.

Resumindo, nesta terceira fase da Transição Epidemiológica, assiste-se ao elevado contributo das doenças crónico-degenerativas e das sociopatias (e.g., as doenças mentais, os suicídios, o alcoolismo, os homicídios). Esta nova fase revela mudanças acentuadas na relação "homem-modo de vida-ambiente" (Remoaldo, 2008).

Em 1989 Henri Picheral avançou com uma quarta fase ao modelo, porque se assistia, nos países mais desenvolvidos, ao recuo das doenças crónico-degenerativas e ao avanço das sociopatias, dos acidentes de tráfego e de algumas Doenças Sexualmente Transmissíveis (e.g., sífilis, gonorreia, A.I.D.S.).

O rápido crescimento das grandes cidades, principalmente das cidades dos países menos desenvolvidos, com um modelo desordenado e espontâneo, possibilitou a deterioração do ambiente urbano, bem como, da qualidade de vida.

Resultado de um processo de urbanização desordenado e do modelo de desenvolvimento económico, com um crescimento da economia excludente e concentrado, que não contemplou as clases sociais menos favorecidas, observamos nas cidades dos países do terceiro mundo agraves sociais. Estes agraves sociais vão determinar o aparecimento de problemas, tais como, a violência e o aumento excessivo de acidentes de trânsito. No entanto, estes problemas podem ser associados aos novos hábitos e estilos de vida adoptados pela sociedade urbana contemporânea. 
No período contemporâneo percebemos também um aumento nas doenças respiratórias, devido ao aumento constante da poluição do ar (Ribeiro, 2004). Nas cidades, o problema do transporte colectivo agrava esta situação, pois quando se tem um deficiente sistema de transporte, o uso do automóvel torna-se imprescindível, além da poluição originária das grandes indústrias. No entanto, em alguns casos, as queimadas que ocorrem próximas a algumas cidades do centro oeste brasileiro têm propiciado o surgimento de problemas respiratórios à sua população residente que habita próximo dessas áreas. Estas novas problemáticas vieram ajudar ao desenvolvimento da Geografia da Saúde quer no Brasil quer em Portugal.

\section{2-NOVAS PERSPECTIVAS PARA A GEOGRAFIA DA SAÚDE BRASILEIRA E PORTUGUESA}

\section{1-A GEOGRAFIA DA SAÚDE NA ACTUALIDADE}

No seio da Geografia contemporânea, a Geografia da Saúde apresenta-se como um subramo que vem cativando cada vez mais novos pesquisadores, principalmente no Brasil, pois a pequena comunidade geográfica portuguesa tem sido um importante handicap ao desenvolvimento deste sub-ramo. Pelo contrário, a extensa comunidade geográfica brasileira e com uma mais prolongada formação em Matemática no ensino não superior, parece permitir uma maior facilidade de adesão a este sub-ramo e à utilização dos Sistemas de Informação Geográfica no campo da saúde.

É perceptível o aflorar de novas discussões que vêm ganhando importância dentro da ciência geográfica, que devem acontecer no intuito de primeiro conseguir a afirmação deste sub-ramo que não é novo, mas que andou esquecido durante muito tempo pela maioria dos Geógrafos brasileiros e portugueses. Em Portugal, ainda que tenha sido um médico (Silva Telles) que primeiro assumiu uma cátedra de Geografia numa Universidade portuguesa (em 1904), tal facto não foi prenúncio de um maior desenvolvimento da Geografia da Saúde. Pelo contrário, seria apenas a partir dos anos setenta e de forma mais consistente a partir dos anos oitenta do século $X X$, que se assistiu à publicação de vários trabalhos científicos, num período em que a ciência geográfica se abria a outras temáticas, tais como, a Geografia do Turismo e a Geografia do Género. São exemplo disso os estudos de (Simões, 1989); (Santana, 1993, 2002, 2005); (Remoaldo, 1993, 1998, 2002, 2008, 2009); (Nogueira, 2001, 2006, 2008, 2009); (Nogueira e Remoaldo, 2009).

Desde, sobretudo o século XIX, que têm sido realizados vários estudos em ciências sociais e em ciências da saúde onde o espaço se afigura como uma componente importante para se perceber a saúde. Os contactos iniciais entre a geografia científica e a epidemiologia, ambas ainda sob a influência predominante da tradição positivista do século XIX, resultou nos primeiros trabalhos sistemáticos de Geografia Médica, voltados para a descrição minuciosa da distribuição regional das doenças, empregando vastos recursos cartográficos. Resultaram deste contacto monumentais atlas de Geografia Médica da segunda metade do século XIX, que orientavam obras de saneamento ambiental e, especialmente, fundamentavam medidas preventivas a serem tomadas pelos exércitos europeus em caso de ocupação militar de territórios insalubres do mundo tropical. Também na segunda metade do século XIX surgem os tratados de climatologia médica, elaborados com maior rigor científico, que procuram correlacionar a ocorrência das doenças, directa ou indirectamente, com aspectos da geografia física, em especial com as variações climáticas.

Tal como aponta (Edler, 2001), no final do século XVIII, percebeu-se o uso de novas práticas higienistas que contribuíram para uma melhoria na qualidade de vida do homem. Segundo (Edler. 2001, p. 928):

Condições naturais podiam ser alteradas diretamente por meio, por exemplo, de secagem de pântanos ou abertura de clareiras em florestas, tornando-se tópicos de grande relevância para os higienistas. Além disso, 
o conhecimento das leis naturais permitiria que as pessoas discernissem os meios de diminuir o impacto da natureza, modificando hábitos antihigiênicos. Ou, como pregavam os higienistas, conformando-se às regras de preservação da saúde. Dois temas centrais para as ciências da vida, em fins do século XVIII, permitiriam o deslanchar do pensamento higienista: a noção de "adaptação" e a idéia de que tanto a vida quanto o meio ambiente tinham uma "história".

Estes tratados serão amplamente referidos por (Sorre, 1955) na elaboração da sua Geografia Médica. Aliás, este Geógrafo foi determinante para a sistematização deste sub-ramo à escala internacional e também para a Geografia brasileira e portuguesa.

No Brasil, nos últimos anos, muito se tem dicutido sobre aspectos nosológicos e das condições de acesso a serviços de saúde. Esta discussão já vem sendo sistematizada de diferentes formas e por diversos especialistas, tais como, (Guimarães, 2001); (Almeida, 2005). Neste momento, a Geografia constitui uma mais-valia no seio desta discussão e tendências mais recentes orientam os estudos voltados para a gestão territorial, planeamento urbano e regional, em especial o urbano. E esta tendência para o "urbano" ganha grande relevância em países como o Brasil, que tal como outros países da América Latina apresentam uma grande concentração da população nas cidades, com os graves problemas que podem decorrer quando estamos a considerar milhões de habitantes em muitas das cidades existentes.

Em Portugal a Geografia dos Cuidados de Saúde também tem vindo a ser pesquisada, sobressaindo os trabalhos de (Santana, 1993) e (Remoaldo, 1998, 2002a, 2002b, 2003) que se preocuparam com a acessibilidade aos serviços de saúde. A temática da A.I.D.S. tem sido investigada por um exíguo número de investigadores, com formação mais sustentada em Geografia Humana. A Tese de Doutoramento de (Nossa, 2005) relacionada com esta problemática para o caso português, demonstra a dificuldade que um investigador tem em avaliá-la num país que, desde os anos noventa do século $X X$, se encontra nos lugares cimeiros em termos de casos de V.I.H. e de mortes por A.I.D.S. por 1.000 .000 de habitantes e no seio da Região Europeia da O.M.S..

A Saúde Reprodutiva é outra das problemáticas que tem sido investigada nos últimos anos, em especial o acesso aos serviços de saúde materna ou infantil (Remoaldo e Canteiro, 2006) e sobre Procriação Medicamente Assistida (Remoaldo, Machado e Reis, 2004, 2006; Remoaldo e Machado, 2007, 2008, 2009). A obesidade começa também a ser abordada em Portugal (Santana, et al., 2006; Santana, Nogueira e Santos, 2007; Santana, Nogueira e Santos, 2008; Santana, Santos e Nogueira, 2009), visto a obesidade infantil ser mais expressiva naquele país do que nos restantes países europeus.

Também é nítida, no âmbito da Geografia brasileira, a afirmação de algumas áreas emergentes, tais como, a Geografia do Turismo, que ocorreu também, como já mencionámos, desde os anos oitenta do século XX noutros países europeus (e.g., Portugal e Espanha). Aliás, se avaliarmos a participação das trinta e quatro comissões da União Geográfica Internacional (U.G.I.), a que se relaciona com o turismo e o lazer mereceu uma importante intervenção no último evento internacional realizado em Tunes, em Agosto de 2008 (31st International Geographical Congress). Foram inúmeras as comunicações no seio da Geography of Tourism, Leisure and Global Changes. Também a Geografia da Saúde (Commission on Health and Environment) foi uma das vertentes mais representativas no mencionado Congresso, tendo contado com a participação de apenas um investigador brasileiro (Raul Guimarães), que se debruçou sobre a difusão da dengue no seu país. Contou ainda com a participação de duas investigadoras portuguesas (Helena Nogueira e Paula Remoaldo), que juntamente com um investigador espanhol 
(Jésus Pérez) se preocuparam com a evolução da Geografia da Saúde à escala da Península Ibérica.

Claro que o destaque desta Comissão derivou também do facto de estar então a decorrer o United Nations International Year of Planet Earth e as questões do Global Environmental Change and Human Health serem determinantes.

Também se observou, derivado dos avanços tecnológicos da sociedade, um aumento significativo dos que trabalham com S.I.G. (Sistemas de Informação Geográfica) e em Geografia Cultural, em especial os estudos voltados para a territorialização de algumas religiões, detendo expressão no Brasil.

A Geografia da Saúde, que se afigura mais abrangente do que a designação de Geografia Médica e que desde 1976 tem adoptado esta designação à escala internacional, tem tido dificuldade em afirmar o seu potencial de estudos quer no Brasil quer em Portugal. Não obstante, há inúmeras áreas que permitem ao Geógrafo a sistematização de estudos capazes de orientarem o planeamento e a gestão de serviços de saúde e que têm em conta as necessidades locais de uma determinada população. Tal orientação constitui-se de grande valia, principalmente, para países menos desenvolvidos, pois, na maioria das vezes, esses países detêm recursos escassos para ofertarem à sua população.

A intensificação dos fluxos de trocas entre regiões impede que estas sejam vistas como autónomas. Para se estudar uma região deve-se compreender as relações, as formas, as funções, as organizações e as estruturas, que envolvem necessariamente a inter-relação das forças presentes em diferentes escalas: local, regional, nacional e global (Santos, 1988, in Barcellos e Machado, 1998).

O lugar permite a compreensão da passagem da escala macro espacial para a micro, no momento em que se percebem as nuances específicas do lugar. Numa sociedade tida como global, em que os ditames são impostos de cima para baixo, faz com que algumas características sejam corrompidas pela influência externa. $\mathrm{Na}$ Geografia, o lugar permite demonstrar aspectos singulares de um determinado espaço.

Ao enfatizar tais características em estudos voltados para a Geografia da Saúde, o lugar destaca-se, pois, algumas doenças vão ser mais intensas ou não mediante as características específicas do lugar. Esse argumento ganha importância na medida em que temos no espaço a associação de diversos factores que vão influenciar na maior ou menor pré-disposição de doenças a que um indivíduo pode estar sujeito em função do lugar onde reside (Barcellos e Machado, 1998).

A N.O.B. (Norma Operacional Básica) 96, apontada nas diretrizes do Sistema Único de Saúde (S.U.S.) do Brasil, coloca os níveis de gestão a que estão submetidos Estados e Municípios, de modo a que o processo de gestão possa atender às características peculiares de cada situação, ou seja, de cada lugar. A progressiva transformação do meio natural em meio científico-técnicoinformacional, agravado pelos meios de produção, tal como aponta Santos (2001, 2004), aumenta a desarmonia na relação homem-meio, e, entre os próprios homens. As deteriorações do espaço, das condições de vida, da saúde e do bem-estar, forçam a convergência profissional de objectivos e enfoques.

A mobilidade espacial é considerada de grande relevância, de acordo com (Becker, 1995, p. 319):

\section{Os deslocamentos de populações em contextos variados e envolvendo ao longo do tempo escalas espaciais diferenciadas conferiram complexidade crescente ao conceito de mobilidade como expressão de organizações sociais, situações conjunturais e relações de trabalho particulares.}

Para a Geografia da Saúde, o conceito de mobilidade espacial expressa a deslocação do indivíduo em relação a um atendimento e isto decorre de uma escala espaço-temporal a nível local. A mobilidade do indivíduo na obtenção de um atendimento médico pode ser associada ao meio de transporte utilizado por ele. Desta forma ressaltase a importância dos meios de transporte público e o benefício que estes podem trazer ao cidadão.

A mobilidade espacial está associada 
a um processo produtivo, uma vez que, as localizações vão ser definidas pela mobilidade do capital. (Corrêa, 1997) argumenta que as redes estão ligadas aos processos produtivos, o que caracteriza a formação das redes territorialmente ligadas à reprodução do capital. A localização de unidades de atendimento de serviços de saúde pode influenciar nesta dinâmica. Isto decorre do facto de que é muito difícil conseguir-se uma boa equidade na distribuição das unidades de serviços de saúde, uma vez que as políticas públicas em saúde levam em conta factores variáveis na elaboração do planeamento da construção de tais unidades. Esta noção foi abordada por (Remoaldo, 2003), colocando a seguinte questão: Será possível uma verdadeira igualdade de acesso a serviços e equipamentos que ocupam pontos discretos no espaço geográfico? A resposta mais realista é Não.

Em geral, os estudos sobre mobilidade espacial são associados a processos migratórios, enfatizando os deslocamentos populacionais nas suas diferentes acepções. Outro conceito de grande valia nos estudos em Geografia da Saúde, mas de difícil conceptualização é o de acessibilidade. Para (Remoaldo, 2001, p. 02) a acessibilidade aos cuidados de saúde, "constitui um conceito muito complexo, multidimensional, de certo modo até movediço, encerrando várias vertentes, que, quase nunca, são consideradas nos trabalhos que têm sido realizados desde, essencialmente, os anos oitenta do século XX".

(Remoaldo, 2003) e (Baleiras e Ramos, 1992), ressaltam no âmbito da acessibilidade aos cuidados de saúde, sobretudo, os factores físico-geográficos (e.g., a distância a percorrer, o tempo gasto no percurso, a disponibilidade de transportes, a localização das paragens dos transportes públicos, a existência de locais de estacionamento), os factores estruturais e funcionais (e.g., a localização dos serviços no mesmo piso do edifício, a existência de elevadores e/ou rampas, os horários de funcionamento e de consultas) e os factores económicos e sócioculturais (e.g., dispêndio de recursos, comunicação eficaz e eficiente entre o profissional de saúde e utente, com utilização de linguagem acessível, conhecimento dos valores, crenças e práticas sociais e de saúde da população).
Esta postura aproxima-se da perspectiva da Organização Mundial de Saúde que desde há décadas aconselha que cada estado-membro meça a acessibilidade aos serviços de saúde em termos físicos (distância, tempo de percurso), económicos (custo da viagem, preço dos serviços) ou sócio-culturais (diferenças de casta, barreiras linguísticas).

Também para grande parte dos autores, a palavra acessibilidade aparece relacionada com a noção de continuidade dos cuidados de saúde, podendo a acessibilidade ser considerada como um requisito imprescindível para que possa haver uma continuidade nos cuidados de saúde. A acessibilidade pode ser encarada num contexto de que "as pessoas que precisam recebam cuidados".

\section{2-O ATRASO CONCEPTUAL VERSUS DESENVOLVIMENTO EMPÍRICO EO CONTRIBUTO DE VÁRIAS INSTITUIÇÕES}

Quem investiga em Geografia da Saúde constata o atraso que durante muitas décadas se fez sentir na conceptualização do seu objecto de estudo e nos seus campos de interesse, comparativamente com o seu desenvolvimento empírico (Remoaldo, 2002).

A Geografia da Saúde constituiu, assim, uma área da Geografia que tem tido dificuldade em se afirmar e em cativar elementos para sua investigação. Será que os geógrafos têm alguma incapacidade em lidar com os termos técnicos médicos usados nos estudos de saúde? Ou será porque se trata de uma abordagem, para a qual muitos têm opinado e poucos conseguem encontrar soluções, como é o caso da acessibilidade aos cuidados de saúde e a eficiência do Sistema Único de Saúde (S.U.S.)? E onde está a participação activa da população nos órgãos de planeamento e gestão de serviços em saúde?

Por seu turno, e como referenciámos anteriormente, os Geógrafos da Saúde estão convictos de que podem desempenhar um papel específico nas ciências da saúde e nas ciências sociais. Isto advém de aspectos metodológicos inerentes à ciência geográfica, tais como, a abordagem da dinâmica espacial e a sua capacidade para representar espacialmente (cartografar) 
e habilidade para analisar simultaneamente a dimensão dinâmica e espacial de fenómenos como epidemias (Remoaldo, 2008).

Numa abordagem pautada pela sociologia, (Freyre, 1983) abordou questões relacionadas com o clima tropical do Brasil, bem como, os aspectos de cunho sócio-cultural e histórico para analisar a situação da saúde, apontando a urbanização e a industrialização como causa para o agravamento dos problemas médico-sanitários no Brasil.

No Brasil, a Economia, influenciada pela ciência demográfica, é uma das ciências que tem apresentado vários estudos em Economia da Saúde. Esses estudos têm levado em consideração temas, tais como, a fecundidade, a esperança de vida, a tipologia socioeconómica e as suas implicações nas condições de acesso a serviços de saúde, a distribuição geográficas de serviços de saúde, a desigualdade social sobre os serviços de saúde (consultar publicações da A.B.E.P. Associação Brasileira de Estudos Populacionais - disponíveis em www.abep.br, e CEDEPLAR, textos para discussão, disponíveis em www. cedeplar.br). A produção científica apresentada nos eventos realizados pela Associação Brasileira de Estudos Populacionais, bem como, por alguns departamentos de Economia de algumas universidades federais têm contribuído, de sobremaneira para uma melhor avaliação da acessibilidade aos serviços de saúde. Também a produção científica do CEDEPLAR (Centro de Desenvolvimento de Planejamento Regional da Universidade Federal de Minas Gerais), tem sido significativa e sustentada pela apresentação de dissertações e teses em Economia da Saúde.

Em Portugal, a Economia da Saúde encontra-se bastante desenvolvida e realiza encontros científicos nacionais, desde pelo menos, os anos oitenta do século XX. Constitui, aliás, um destacado lobby no seio das ciências sociais.

A FIOCRUZ (Fundação Oswaldo Cruz) é um importante centro de estudos da saúde, sediado no Rio de Janeiro. Este centro é de referência nacional e até mesmo mundial em algumas pesquisas. Possuiu ampla tradição em estudos relacionados com a medicina tropical, bem como, com demais ramos relacionados com a saúde, como a saúde pública e a epidemiologia. Abriga uma equipa interdisciplinar no seu quadro de pesquisadores, formada, entre outros, por médicos, sociólogos, geógrafos e biólogos. Sobressaem no seio desta equipa, os professores Christovam Barcellos pesquisador titular Fundação Oswaldo Cruz, (FIOCRUZ/RJ), Brasil. Na mesma instituição encontra-se o pesquisador Paulo César Peiter (vencedor, em 2006, do prémio CAPES de melhor tese de doutoramento em Geografia), com a tese intitulada "Geografia da saúde na faixa de fronteira continental do Brasil na passagem do milênio". O CAPES (Coordenação de Aperfeiçoamento de Pessoal de Nível Superior), é um orgão do governo brasileiro que visa a melhoria da pós-graduação brasileira, através de avaliação, divulgação, formação de recursos e promoção da cooperação científica internacional.

Outra fonte importante de dados é disponibilizada pelo I.B.G.E. (Instituto Brasileiro de Geografia e Estatística), que produz relatórios a nível nacional referentes à saúde da população brasileira.

Segundo (Guimarães, 2001), no encontro da Associação dos Geógrafos Brasileiros (A.G.B.), realizado em Julho de 2000, em Florianópolis, em Santa Catarina, foi promovida uma mesa redonda em que foi privilegiada a discussão da Geografia e Saúde. Destacam-se estudos de autores, antes desta fase, não só de Geógrafos como também de economistas, Sociólogos, Médicos que já tinham nos seus estudos a preocupação da análise da saúde em relação ao espaço.

A Escola Nacional de Saúde Pública da Universidade Nova de Lisboa constitui uma boa referência portuguesa do que se pode investigar em saúde, sobressaindo o papel de vários professores, médicos, sociólogos e economistas que vão publicando na Revista Portuguesa de Saúde Pública, de grande credibilidade científica.

No Brasil, destaca-se ainda o Instituto de Geografia da Universidade Federal de Uberlândia, que criou sob a tutela do Professor Samuel Lima, o 
Laboratório de Geografia Médica. Outro pesquisador que se destaca no mesmo departamento é o Professor Julio César Ramires. Neste mesmo departamento foi criado um periódico intitulado HYGEA - Revista Brasileira de Geografia Médica e da Saúde, com publicação de pesquisadores de várias áreas e departamentos que se dedicam à investigação dos aspectos da saúde.

$\mathrm{Na}$ Universidade Estadual de São Paulo, campus Presidente Prudente destaca-se o Professor Raul Borges Guimarães, que tem produzido e orientado varias monografias, dissertações e teses em Geografia Médica e da Saúde. O mesmo tem como objecto de estudo políticas públicas em saúde tendo subjacente uma análise geográfica, além de ser pesquisador de um importante centro de estudo - o CEMESPP (Centro de Estudos do Mapeamento da Exclusão Social para Políticas Públicas). Este Centro conta com a participação de vários profissionais que se interessam pelo estudo da saúde.

Um ramo de estudo que já vem sendo analisado por alguns geógrafos brasileiros diz respeito ao mapeamento de acidentes e violências, destacando-se o Professor Jan Bituon, da Universidade Federal de Pernambuco e a Professora Márcia Siqueira da Universidade Estadual de Londrina.

\section{3-ALGUNS CAMINHOS PARA A GEOGRAFIA DA SAÚDE BRASILEIRA E PORTUGUESA}

É incontornável o facto da Geografia da Saúde se assumir como um ramo de estudo fecundo para a ciência geográfica. No entanto, alguns aspectos devem ser relevados para a afirmação desta área. Em primeiro lugar, é necessária a introdução da disciplina nos curricula dos cursos de Geografia, tanto no bacharelado quanto na licenciatura.

Em Portugal ela já existe, como diciplina de opção em duas licenciaturas de Geografia desde 1995 (Universidade de Coimbra) e 1998 (Universidade do Minho - Quadro 1) e também como disciplina opcional no Mestrado em Sociologia (Área de Especialização em Saúde e Sociedade) da Universidade do Minho.

No Brasil, salientamos a presença da Geografia da Saúde como disciplina opcional no Bacharelato de Geografia da Unesp Presidente Prudente. Também em vários departamentos como disciplina de pós-graduação em Geografia, ressaltando o Instituto de Geografia da Universidade Federal de Uberlândia (Diciplina de Geografia Médica e Vigilância em Saúde) e o Departamento de Geografia da Unesp Presidente Prudente (Abordagens Geográficas da Saúde Ambiental).

\begin{tabular}{|lll|}
\hline Elementos analisados & Brasil & Portugal \\
\hline $\begin{array}{lll}\text { Principais temáticas } \\
\text { investigadas nas últimas } \\
\text { décadas }\end{array}$ & Regionalização e & H.I.V./A.I.D.S.; \\
& Saúde; S.I.G. e Saúde; & Cancer; Acesso, Uso \\
& Geoprocessamento & e Satisfação com os \\
& e Saúde; Geografia & cuidados de saúde; \\
& da Saúde e Aspectos & Saúde Reprodutiva \\
& Ambientais; Doenças & e Saúde Infantil; \\
& Infecciosas e & Promoção de Cidades \\
& Parasitárias; Alterações & Saudáveis; Actividade \\
& Climáticas e Saúde; & Física e Promoção da \\
& Redes de Serviços & Saúde; Infertilidade. \\
& de Saúde; Políticas & \\
& Públicas e Impactos & \\
& Territoriais em Saúde. & \\
Anód oitenta do seculo & Anos oitenta do século \\
estruturada realizada sobretudo & XX. & XX. \\
nas Universidades & &
\end{tabular}




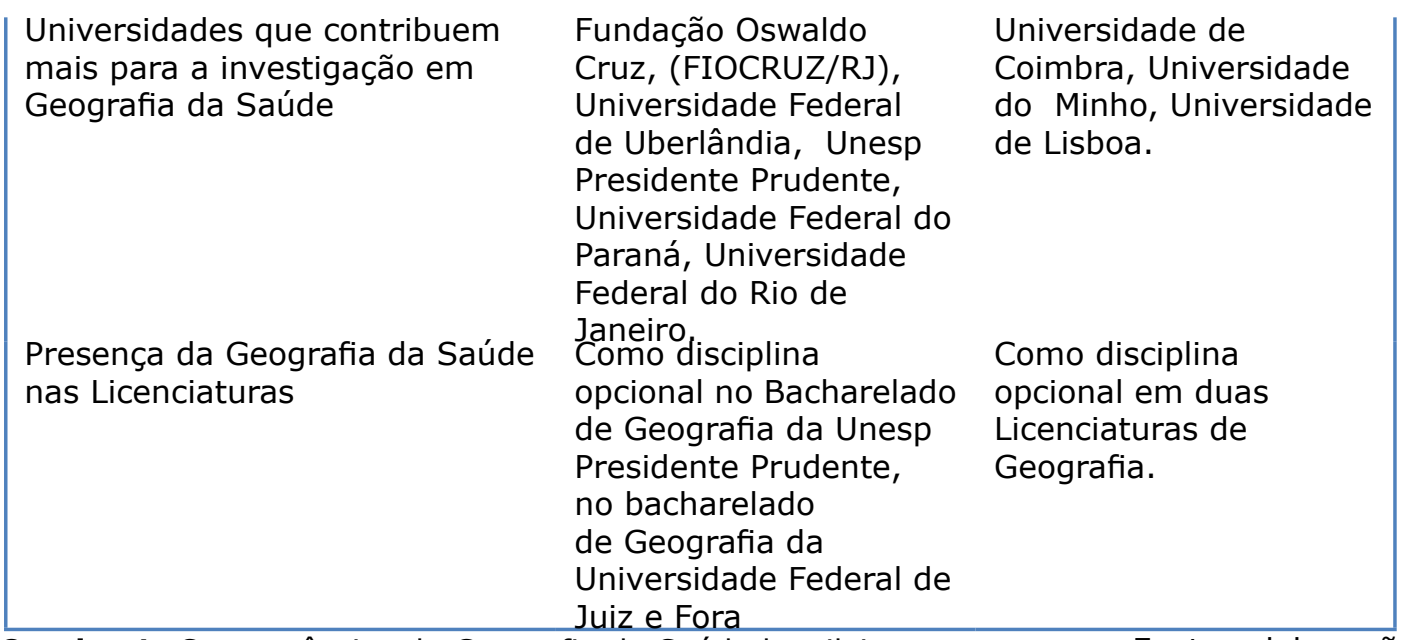

Quadro 1: Convergências da Geografia da Saúde brasileira e portuguesa -Fonte: elaboração própria.

Em segundo lugar, devem ser realizados mais esforços para os Geógrafos trabalharem em equipa no seio de cada país e em redes transnacionais. Entre 28 e 30 de Novembro de 2005 foi realizada uma primeira tentativa, no Rio de Janeiro, no II Simpósio Nacional de Geografia da Saúde e I Encontro Luso-brasileiro de Geografia da Saúde intitulado "A Geografia e o contexto dos problemas de saúde", organizado pela Fundação Oswaldo Cruz (Fiocruz - Ministério da Saúde), pela Associação dos Geógrafos Brasileiros (A.G.B.) e pela Associação Brasileira de Pós-Graduação em Saúde Colectiva (ABRASCO), mas o intercâmbio mais sutentável e a elaboração de projectos em comum ainda não se concretizou.

Entretanto, ocorreu recentemente o II Congresso Internacional e IV Simposio Nacional de Geografia da Saúde, que se realizou entre os dias 30 de Novembro e 3 de Dezembro de 2009 na Universidade Federal de Uberlândia, Minas Gerais, evento que contou com a presença diminuta de Geógrafos portugueses. De qualquer modo, tratase de uma importante iniciativa, pois em Portugal não foram ainda realizados eventos nacionais que se dediquem somente à questão da Geografia da Saúde, decorrente, entre outros aspectos, da pequena comunidade geográfica existente e do exíguo número de Geógrafos que se debruçam apenas sobre a questão da saúde.
Em terceiro lugar, os Geógrafos devem tentar assumir mais um papel de coordenação no seio de equipas multidisciplinares, que são, normalmente, lideradas por Médicos e Economistas.

Por último, o Geógrafo deve mostrar e provar à sociedade a aplicabilidade da análise territorial a diferentes escalas, no que concerne a saúde, já que é fácil para eles analisar vários atributos geográficos, tais como, a segregação espacial ou as iniquidades sociais.

Várias são as possibilidades de investigação em Geografia da Saúde. O investigador pode elaborar estudos que vão desde a disseminação de epidemias, tais como, a dengue e a tuberculose. Este tipo de estudos estão já a ser desenvolvidos em alguns departamentos de Geografia no Brasil.

Cabe ressalvar que este ramo de estudo necessita que o investigador se depare com a discussão de conceitos oriundos de outras ciências, tais como, a Medicina, outras ciências sociais e a Epidemiologia. Esses conceitos são complexos e devido a um atraso epistemológico em Geografia da Saúde, os Geógrafos têm que incorporar, nas suas referências epistemológica e metodológica, conceitos como o de doença, patologia, acesso e utilização de serviços e vários aspectos de morbilidade da população.

No caso português, as questões 
da obesidade continuarão a atrair jovens investigadores, pelos motivos que já invocámos. As questões epistemológicas da Geografia da Saúde à escala da Península Ibérica também parecem começar a preocupar alguns investigadores e alguns deles estão a começar a trabalhar em equipa (Remoaldo, Nogueira e Pérez, 2010). E têm emergido cada vez mais trabalhos que avaliam a influência do lugar (place) nos comportamentos alimentares dos indivíduos, facto que segue algumas das tendências da investigação à escala internacional. Preocupam-se, por exemplo, com a avaliação do local de residência das crianças, em termos de condições para a realização de actividade física (envolvente da residência), quer sejam institucionalizadas ou não (e.g., ginásios, campos de futebol, caminhos pedestres, ciclovias, existência de passeios nas vias). Centram-se, por outro lado, na avaliação dos equipamentos existentes e na identificação dos espaços mais deficitários. Por último, tentam propor áreas de intervenção a curto prazo, no sentido de melhorar a rede de equipamentos e infra-estruturas que permitam a realização de exercício físico e o desenvolvimento de uma vida mais saudável (e.g., Monteiro, 2009).

No Brasil, depois das investigações se terem direccionado preferencialmente para as questões da acessibilidade aos cuidados de saúde, esta temática passou a estar associada aos Sistemas de Informações Geográfica (S.I.G.). Outra vertente de estudos desenvolvida em várias regiões do Brasil está relacionada com o estudo das doenças infecciosas e parasitárias, destacandose o Dengue, a Malária, associando a Geografia da Saúde às questões ambientais. As questões climáticas e as suas relações com o estado de saúde é uma temática que está sendo trababalhada nos últimos anos, sobressaindo os trabalhos de (Ribeiro, 1996) e (Moraes, 2007).

As questões que envolvem as acessibilidades, redes, localização de equipamentos de saúde constituem alguns temas que estão a aflorar nos estudos de Geografia da Saúde. Um domínio de investigação ainda deficitário é o da epistemologia da Geografia da Saúde. Começamos a dar os primeiros passos nas questões do envelhecimento, da herança cultural e noutras vertentes da Educação para a Saúde, bem como, na abordagem das políticas públicas e seus impactos socioespaciais. O futuro dirá se estas novas temáticas irão possibilitar a sistematização de estudos que abrangem a realidade espacial e se irão contribuir para a melhoria da qualidade de vida da população por meio da promoção da saúde.

\section{3-CONCLUSÕES}

Na nossa análise tentámos demonstrar o que a Geografia representa para a sociedade, ou seja, a sua importância como ciência social, ganhando um novo élan quando trazemos para a sua abordagem a questão da doença e da saúde. Infelizmente, só nas últimas décadas emergiu como sub-ramo no seio da Geografia, e recentemente passou a agregar cada vez mais pesquisadores interessados em desenvolverem estudos ligados à saúde.

No âmbito desta ascensão fica a necessidade de rever questões de cunho teóricometodológico para que a Geografia da Saúde ganhe o seu espaço no seio da sociedade. Desta forma, podemos ver em órgãos de governo brasileiros (tanto à escala federal, estadual como municipal) ligados a políticas de planeamento da saúde, o trabalho de Geógrafos, não somente usando ferramentas para mapeamento, mas utilizando técnicas de mapeamento como um atributo a mais para oferecer à população uma saúde melhor.

No Brasil, visto que o desenvolvimento da Geografia da Saúde é muito recente e são exíguos os trabalhos desenvolvidos, ainda estamos a dar os primeiros passos neste domínio. Assim, depois das investigações se terem direcionado preferencialmente para as questões da acessibilidade aos cuidados de saúde (nas suas diversas vertentes) e para a disseminação de algumas epidemias, começamos a dar os primeiros passos nas questões do envelhecimento, da herança cultural e noutras vertentes da Educação para a Saúde. O futuro dirá se estas novas temáticas poderão cativar novos Geógrafos brasileiros.

No que concerne à Geografia da Saúde portuguesa, apesar de contar actualmente com um número reduzido de investigadores, que não 
ultrapassa os quatro e concentrados em apenas duas Universidades (Universidade de Coimbra e Universidade do Minho), tem conseguido, neste novo milénio, comunicar de forma mais efectiva com os profissionais de saúde. Estes, sempre se assumiram como uma comunidade fechada, sobretudo os médicos, e pouco interesse revelaram durante muito tempo pelo contributo que os Geógrafos podem dar na análise da saúde. Não obstante, a descoberta da escala mais local e do potencial dos Sistemas de Informação Geográfica vieram alertá-los para a necessidade de trabalharem em conjunto com os Geógrafos.

\section{Bibliografia}

ALMEIDA, Eliza Pinto de. O Uso do Território Brasileiro e a Segmentação dos Serviços de Saúde. IN: Anais do X Encontro de Geógrafos da América Latina. São Paulo, p. 402-420, 2005.

BALEIRAS, S.J.; RAMOS, V.. A gestão da prática clínica pelo médico de família, in "Revista Portuguesa de Clínica Geral", Lisboa, 9(4), pp. 116-124. Abril 1992.

BARCELLOS, Christovam ; MACHADO, Jorge M. Huet. A organização espacial condiciona as relações entre ambiente e saúde: o exemplo da exposição ao mercúrio em uma fábrica de lâmpadas fluorescentes. Ciência \& Saúde Coletiva, 3(2):103-113, 1998.

BECKER, B. K.. A Geopolítica na Virada do Milênio: Logística e Desenvolvimento Sustentável. In: Castro, I. E.; Gomes, P. C. C.; Corrêa, R. L.. (Org.). Geografia: Conceitos e Temas. Rio de Janeiro: Bertrand Brasil, 1995, p. 271-307.

BOUSQUAT, A. ; COHN, A. A dimensão espacial nos estudos sobre saúde: uma trajectória histórica. História, Ciências, Saúde. Manguinhos, vol. 11(3): 549-68, set.-dez. 2004.

BRAUDEL, Fernand. Civilização,material e economia. Rio de Janeiro: Bertrand Brasil, 1995.

CASAS, Susana I. Curto de. La Argentina Ambiental, Naturaleza y Sociedade. Buenos Aires: Lugar Editorial, p. 191-204, 1998.

CLAVAL, Paul. A Nova Geografia. Coimbra: Almedina, 1982.
CORBUSIER, LE. O Urbanismo. São Paulo: Martins Fontes, 2000, $2^{\mathrm{a}}$ ed.

CORRÊA, Roberto Lobato.Trajetórias Geográficas. Rio de Janeiro: Bertrand Brasil, 1997.

CORRÊA, Roberto Lobato. O espaço urbano. São Paulo: Editora Ática, 2000.

CORRÊA, Roberto Lobato. Espaço: conceito-chave da geografia. ORG. CASTRO, Iná E.; GOMES, P. C. da Costa ; CORRÊA, R. L.. IN Geografia: Conceitos e Temas. Rio de Janeiro: Bertrand Brasil, 2003.50 ed.

CZERESNIA, D.; RIBEIRO, A. M.. O conceito de espaço em epidemiologia: uma interpretação histórica e epistemológica. Cad. Saúde Pública., Rio de Janeiro, v. 16, n. 3, p. 595 - 617, Jul./Set. 2000.

EDLER, F. C.. De olho no Brasil: a geografia médica e a viagem de Alphonse Rendu. História, Ciências, Saúde. Manguinhos, vol. VIII (suplemento), p. 925-943, 2001.

FERREIRA, Marcelo Urbano. Epidemiologia e geografia: o complexo patogênico de Max. Sorre. Cad. Saúde Pública v.7 n.3 Rio de Janeiro jul./ sep. 1991.

FREYRE, Gilberto. Médicos, doentes e contextos sociais: Uma abordagem sociológica. Rio de Janeiro: Editora Globo. 1983.

GUIMARÃES, Raul Borges. Saúde Urbana: velho tema, novas questões. In. Terra Livre n. ${ }^{\circ} 17 . P .155-$ 170. $2^{\circ}$ semestre 2001 .

HOUAISS, Antonio; VILLAR, Mauro de Salles. 
Dicionario Houaiss de Lingua Portuguesa. Rio de Janeiro: OBJETIVA, 2001.

MORAES, Paulo Roberto. As áreas tropicais úmidas e as febres hemorrágicas virais- Uma Abordagem Geográfica e Ambiental na Saúde. e doenças respiratórias em criança da Grande São Paulo: um estudo de geografia médica. São Paulo: São Paulo: Faculdade de Filosofia, Letras e Ciências Humanas da Universidade de São Paulo, 2007. 339 p. Tese de doutorado em geografia, Departamento de geografia.

NOGUEIRA, H.. Os lugares e a Saúde - Uma abordagem da Geografia às variações em saúde na Área Metropolitana de Lisboa. Faculdade de Letras da Universidade de Coimbra, Portugal, 2006. 483 p.. Tese de doutoramento em Geografia.

NOSSA, Paulo Nuno M. de Sousa. Abordagem geográfica da oferta e consumo de cuidados de saúde. Instuto de Ciências Sociais da Universidade do Minho, Braga, Portugal. 2005. 411p.. Tese de doutoramento em geografia.

PEITER, Paulo César. A Geografia da Saúde na Faixa de Fronteira Continental do Brasil na Passagem do Milênio. Rio de Janeiro. Universidade Federal do Rio de Janeiro UFRJ Instituto de Geociências Programa de Pós-Graduação em Geografia, 2005. 334 p.. Tese de doutorado em Geografia.

PESSOA, S. B. Ensaios Médico-Sociais. São Paulo: CEBES/Editora Hucitec, 1978.

PÉREZ, J.M.G. Presentació - Geografía de la Salud, in "Territoris - Revista del Departament de Ciències de la Terra", Universidade das Ilhas Baleares, Maiorca, n.5, p. 7-15, 2002.

PICKENHAYN, Jorge A. Geografía para la salud: una transición. Algunos ejemplos de caso Argentino. In: LEMOS, Amália Inés Geraiges de; SILVEIRA; María Laura; ARROYO,Mônica (org.). Questões territoriais na América Latina. Buenos Aires: Ed. Clacso e editora Expressão Popular, 2006.

PICHERAL, H.. La Géographie de la Santé. in BAILLY, A., et al., Les concepts de la Géographie
Humaine, 5e éd., Paris : Armand Collin, 2001, p. 229-240.

REMOALDO, Paula, Cristina A.; NOGUEIRA, Helena. Olhares geográficos sobre a saúde. Porto: Edições Afrontamento, 2010 (no prelo).

REMOALDO, Paula Cristina A. Aspectos sociodemográficos e nosológicos da população do serviço de urgência do hospital de Guimarães. Separata de Geografia, Revista da Faculdade de Letras da Universidade do Porto. I série, Vol. IX, 1993.

REMOALDO, Paula Cristina A.. "Acessibilidade física, funcional e econômica aos cuidados de saúde". CD-ROM das Actas do IV Congresso da Geografia Portuguesa - Geografia: Territórios de Inovação, Lisboa, Associação Portuguesa de Geógrafos, 15 págs. 2002.

REMOALDO, Paula Cristina A. Desigualdades territoriais e sociais subjacentes à mortalidade infantil em Portugal. Série Textos Universitários de Ciências Sociais e Humanas, Lisboa, Fundação Calouste Gulbenkian, Ministério da Ciência e da Tecnologia (Fundação para a Ciência e a Tecnologia), 2002. 586 p.

REMOALDO, Paula Cristina A.. Acessibilidade física, funcional e económica aos cuidados aos cuidados de saúde, CD-ROM das " Actas do IV Congresso da Geografia Potuguesa- Geografia: Territórios de Inovação", Lisboa, Associação Portuguesa de Geográfos, 2002 a, 15 p.

REMOALDO, Paula Cristina A.; COSTA, M.E.S. Equidade no acesso aos cuidados de saúde - resultados de dois inquéritos realizados à população, "Actas do Colóquio Internacional de Saúde e Discriminação Social", Leandro, M.E., et al. (coord.), Braga, Instituto de Ciências Sociais, Universidade do Minho. p. 71-90, 2002b.

REMOALDO, Paula Cristina A.. "Acessibilidade aos cuidados de saúde dos concelhos de Guimarães e de Cabeceiras de Basto". Revista Portuguesa de 
Clínica Geral, Lisboa, no 19, págs. 107-119, 2003. REMOALDO, Paula Cristina A.. Geografia da Saúde portuguesa - sonhos e realidades, "Territoris Revista del Departament de Ciències de la Terra", Número monográfico sobre a Geografia de la Salut, Universidade das Ilhas Baleares, Maiorca, n.5, pp. 33-48, 2005.

REMOALDO, Paula Cristina A.; MACHADO, Helena. O sofrimento oculto - causas, cenários e vivências da infertilidade, Porto: Edições Afrontamento, 2008.

REMOALDO, Paula Cristina A.. Geografia da Saúde, $2^{a}$ ver., Curso de Geografia, Guimarães, 2008, 199 p. (policopiado).

REMOALDO, Paula Cristina A.; NOGUEIRA, Helena; PÉREZ, J.G.. Health Geography on the Iberian Peninsula: a view since the John Snow map, 2010, 23 p. (proposto para publicação).

RIBEIRO, Helena. Saúde Pública e Meio Ambiente: evolução do conhecimento e a prática, alguns aspectos éticos. IN. Saúde e Sociedade v.13, n.1, p.70-80, jan-abr 2004.

RIBEIRO, Helena. Poluição do ar e doenças respiratórias em criança da Grande São Paulo: um estudo de geografia médica. São Paulo: Faculdade de Filosofia, Letras e Ciências Humanas da Universidade de São Paulo, 1988, p. 4-98.Tese de doutorado em geografia, Departamento de geografia.

RIBEIRO, Helena. Ilha de calor na cidade de São Paulo: sua dinâmica e efeitos na saúde da população. São Paulo. Faculdade de Filosofia, Letras e Ciências Humanas Universidade de São Paulo, 1996.144p. Tese de Livre Docência.

SANTANA, P., et al. Impacts of Urbanization on Weight Gain and Obesity in Portugal. In: R.
González (ed.), Urban Changes in Different Scales: Systems and Structures. Santiago de Compostela, Publicacións Cursos e Congressos da Universidade de Santiago de Compostela, 169, p. 275-286, 2006.

SANTANA, P.; NOGUEIRA, H.; SANTOS, R. Ambientes Obesogénicos: Contexto, Mobilidade e Dieta. In: P. Santana (coord.), A Cidade e a Saúde. Coimbra, Edições Almedina, pp. 143-154, 2007.

SANTANA, P.; NOGUEIRA, H.; SANTOS, R.. Comunidades sustentáveis: impacte do contexto social e material no aumento de peso e obesidade. In. Revista Brasileira de Ciências Ambientais, p. 23-29, 2008.

SANTANA, P.; SANTOS, R.; NOGUEIRA, H. The link between local environment and obesity: a multilevel analysis in the Lisbon Metropolitan Area, Portugal. Social Science and Medicine, 68, p. 601609, 2009.

SANTOS, Milton. ORG. Os novos rumos da geografia brasileira. São Paulo: Hucitec, 1982.

SANTOS, Milton e SILVEIRA, Maria Laura. O Brasil: Território e sociedade no século XXI.São Paulo e Rio de Janeiro: Editora Record, 2001.

SANTOS, Milton. A Natureza do Espaço: razão e emoção, técnica e tempo. São Paulo: $4^{\circ}$ edição, Edusp, 2004.

SORRE. M. Fundamentos Biológicos de la geografia humana. Ensayo de una ecologia del Hombre. Barcelona: Juventud, 1955.

URTEGA, Luiz. Miseria, miasmas y microbios. Las topografías médicas y el estúdio Del médio ambiente em El siglo XIX. Geocritica, Universidade de Barcelona, ISSN: 0210-0754. Año V. Número: 29, Noviembre de 1980. Disponível na internet. WWW.ub.es/geocrt/menu.htm. 